\title{
Testing psychological trivia
}

\author{
HENRY L. ROEDIGER III and TERESA A. BLAXTON \\ Purdue University, West Lafayette, Indiana
}

\begin{abstract}
A description is provided of a test for general knowledge of obscure facts from the history of psychology. Included are 120 questions that comprise the test, along with their answers. The test contains such questions as "What was the name of Clever Hans' owner?" "What researcher first coined the term 'reaction time'?" "In what year did Pavlov receive the Nobel prize?" Important uses for the test are suggested. All proceeds from the test will be donated to The Psychonomic Society.
\end{abstract}

Faithful readers of this journal need not be reminded that many pursuits in psychology are trivial ones. Why publish an article based explicitly on this premise, even announcing it in the title? Briefly, we have developed a test of psychological trivia. Its resemblance to other games currently being marketed in various forms is purely coincidental, of course. Our test, known as TPT (Testing Psychological Trivia), follows a long tradition of testing within psychology, for its reliability is unknown, its validity uncertain, and its effectiveness as a predictor of anything important probably quite laughable. In short, it has the same general psychometric properties of the Rorschach, MMPI, and other established psychological tests.

The test, as currently formulated, consists of 120 items testing random bits of knowledge about psychology, mainly general history. Our test reflects the biases of its makers, again in the time-honored tradition of test construction. The intellectual flotsam and jetsam we have collected here has been appropriated, culled, and stolen from many sources, mostly from histories of psychology. It is biased toward experimental psychology rather than other varieties, although we include a smattering of esoteric knowledge from other fields. Some items require an answer to be recalled based only on the question as a source of cues; others that we deemed more difficult we converted into multiple choice items in an effort to be helpful.

How should one use the test? Many types of games are possible, but we have had success with the following variety. ${ }^{1}$ A group of people is divided into teams of two to four players; we recommend three to five teams. One team is selected by some random means to begin, and an order in which teams will receive questions is established. (We suggest clockwise rotation, but counterclockwise ordering permits an interesting variation.) The first question is asked of the first team. If they can answer it aloud within the $30-\mathrm{sec}$ time period, they win two points and the next team receives the second question. If, however, the first team fails, then each of the other teams is also permitted to respond to the first question. The first team

Requests for reprints and royalty donations may be made in care of the first author at the Department of Psychological Sciences, Peirce Hall, Purdue University, West Lafayette, IN 47907. to venture the correct answer wins two points; however, a point is lost for every incorrect answer. This penalty ensures that frivolous guesses will be kept to a minimum and that a proper sense of decorum will accompany the game. (The team originally asked the question is permitted to answer a second time; for them the first answer carries no penalty point, but succeeding incorrect answers do.) The game continues in this manner until either the questions or the participants are exhausted. The team with the highest total wins the title "Masters of Psychological Trivia," suitable for inclusion on vitae under "Professional Accomplishments."

Of course, we hardly mean to imply that TPT is useful only for gameplaying, any more than is the Rorschach. Other possible applications include the game's use as a selection device for determining (a) receipt of a B.S. or B.A. in psychology, (b) entry into graduate school, and (c) tenure decisions. The test may also be used as an obtrusive device for predicting career success of graduate students, and thus as an effective aid in hiring.

We now turn to a delicate matter, that of royalties for use of our test. We had considered making up a few more questions, developing a silly cardboard surface with squares, manufacturing little game pieces ("psyches" and "psychos") to be placed on the board, establishing nonsensical rules for moving the pieces around the board, and constructing questions that all end in prepositions. Then we could charge $\$ 30$ for our creation. However, this approach seemed too crass. Thus, we have decided to operate on the honor system, because the members of The Psychonomic Society are, like the Mafia, an honorable lot when dealing with their conspecifics. Our royalty system is simple. If you play yourself, then you need only mail us a check for $\$ 5$. However, if a group of two to seven people plays the game, then the charge is $\$ 15$. If more than seven play, please remit $\$ 25$. All proceeds will be donated to The Psychonomic Society, the leading organization for furthering psychological truth in the second half of the twentieth century. Checks may be made payable to The Psychonomic Society and sent to the first author.

The 120 items of TPT appear below, with the answers following them. Our painstaking research shows that once 
the answers have been presented in conjunction with the questions, players perform better on subsequent tests. This phenomenon, sometimes known as "priming," might be of interest to researchers concerned with learning and memory. By the way, in order to enhance the external validity of our test and make it similar to those on the open market, answers to some questions may be incorrect, or at least arguable. If you have comments (or additional questions for us), please send them along. Should this "Old Timers" version of the test prove successful, we plan to issue a "Baby Boomers" edition at a future date.

\section{TPT}

1. Where did B. F. Skinner go to college?

2. Who founded act psychology?

3. In what year did Ebbinghaus begin his research published in $O n$ Memory, and when was the book published?

4. Only two people have been twice elected to be President of the APA. Name them.

5. Who first coined the term "stimulus error"?

6. Who invented the term "mental test"?

7. Name the psychologist who (a) received his Ph.D. at Harvard under William James, (b) became a leading functionalist at Chicago, (c) was elected President of APA in 1906, and (d) served as President of Yale University from 1921-1937.

8. Whose doctoral dissertation was entitled, "Animal Education: The Psychical Development of the White Rat"?

9. On what island was Wolfgang Köhler trapped during WWI?

10. Who coined the term "intervening variable"?

11. Where did Clark Hull receive his Ph.D.?

12. Where did Karl Lashley receive his Ph.D. and with whom?

13. Name all of the authors of Frustration and Aggression.

14. In what year did Pavlov receive the Nobel Prize?

15. In what year was the Journal of Experimental Psychology first published, and who was its first editor?

16. Psychological Review first appeared in 1894 . Who were the first coeditors?

17. What was the original name of the Journal of Comparative Psychology?

18. Who wrote in a letter the following confession?

"I naturally hate experimental work, but all my circumstances conspired (during the important years of my life) to prevent me from getting into a routine of it, so that now it is always the duty that gets postponed."

a. Kurt Lewin

b. Edward Chace Tolman

c. William James

d. John B. Watson

e. George A. Miller

19. Who was the first female president of the APA, and in what year was she elected? (Incidentally, Harvard refused to grant her a Ph.D. because of her gender; she refused to accept it from Radcliffe.)

20. Which of the following was not a president of the APA?
a. Albert Poffenberger
b. George Stuart Fullerton
c. Joseph Peterson
d. Gordon Allport
e. Samuel W. Fernberger

21. Who is given credit (or blame) for establishing phrenology in the late 1700 s and early 1800 s?

22. Who said, "Psychology has a long past, but its real history is short" (as translated by Boring)?
23. Name two of the six APA Presidents from 1970-1975.

24. Who coined the term "unconscious inference"?

25. Who served as President of the first International Psychoanalytic Society?

26. What famous learning theorist once commented during a seminar, "I get down on my knees every night and pray to God to let me be a machine"?

a. Hull

b. Guthrie

c. Skinner

d. Spence

e. Tolman

27. Hick's Law is generally attributed to a publication in 1952 . Who first demonstrated the phenomenon?

28 . In the late 1800 s, what university refused to permit the establishment of a psychophysics laboratory because study of such a topic would "insult religion by putting the human soul on a pair of scales"?

29. Who wrote the chapter on cognitive processes in S. S. Stevens' (1953) Handbook of Experimental Psychology?

30. Name the first three recipients of the APA's Award for Distinguished Scientific Contributions, given in 1956.

31. What was Robert Woodworth's middle name?

32. What famous experimental psychologist, using the pen name Dr. Mises, wrote satires, such as "Proof the moon is made of iodine," criticizing the use of iodine as a medical panacea?

33. Who said "A man cannot hope to become a psychologist until after he learns to smoke," with the result that most of his students smoked cigars in his presence?

34. Who invented the word association test?

35. Name the husband-wife "team" who won APA's Award for Distinguished Scientific Contribution in separate years.

36. Who founded the American Journal of Psychology and in what year?

37. What was Ivan Pavlov's middle name?

38. Who, after finishing a famous textbook in psychology, wrote his publisher that his book was a "loathsome, distended, tumefied, bloated, dropsical mass, testifying to nothing but facts: (1) there is no science of psychology and (2) the author is an incapable'?

a. James Coleman

b. William James

c. Robert Woodworth

d. B. J. Winer

e. Charles Osgood

39. Which famous student of Wundt's was criticized for giving Wundt a typewriter as a gift because it enabled Wundt to write twice as many books as would have otherwise been possible?

40. When did the first edition of Hilgard's Theories of Learning appear?

41. Who was Albert Bandura's first Ph.D. student?

42. What famous psychologist was prevented from graduating and entering the seminary because he handed in a paper backwards after the professor in the course warned that anyone doing so would fail the course?

43. Which recipient of the APA Distinguished Scientific Contributions Award made the following statement in the American Psychologist? "My doctoral work was cut short by the Berlin Crisis of 1961, which compelled my return to Fort McClellan. There I joined the Chemical Corps and prepared to fight World War I, should it break out again, by learning to decontaminate mustard gas. This military experience was to prove invaluable later in providing insight into the actions of university administrators. Since no libraries or copiers were available at Fort McClellan, I photographed hundreds of pages of articles on long tissue paper rolls. The resulting dissertation won awards at my university and American Institutes for Research, perhaps confirming the proper role for psychological literature. Additional activities in the army included daydreaming my commanding colonel would one day enroll in graduate school." 
44. What mathematician developed the theory of monadology to explain how the unconscious works?

45. In what year did Max Wertheimer publish his paper on the phi phenomenon, thus helping to launch Gestalt Psychology?

Questions 46-54: Name the author and date of publication of the following famous books (one point for each):

46. Perception and Communication

47. Purposive Behavior in Animals and Men

48. The Mentality of Apes

49. On Aggression

50. The Behavior of Organisms

51. Principles of Behavior

52. Personality and Psychotherapy

53. Cats in a Puzzle Box

54. A Dynamic Theory of Personality

55. Other than husband-wife "teams," there have been four surnames represented twice among recipients of APA's Award for Distinguished Scientific Contributions. Name them.

56. Who developed the method of retained members (free recall) for studying memory?

57. Who coined the term "eidetic imagery"?

58. Where did the F-ratio get its name?

59. Who was the first to be credited with using a rating scale to define personality?

60. What is Lloyd Morgan's canon?

61. Who first used the "breakfast table" questionnaire to study visual memory?

62. What was Donders' primary research interest?

63. Who was Rosalie Rayner?

64. Who said, "I stand for an infinitely freer sexual life, although I myself have made very little use of such freedom'?

a. W. Reich

b. B. F. Skinner

c. S. Freud

d. W. H. Masters

65 . When and by whom were the first word association norms published?

66. What researcher first coined the term "reaction time'?

67. What had Skinner chosen as a profession prior to becoming a psychologist?

68. What contemporary of Pavlov was called the "reflexologist"' because he advocated the study of motor CRs over salivary responses?

69. Who designed the stereoscope?

70. Where were Thorndike's first puzzle box experiments conducted?

71. When and by whom was the effect of sleep on retention first experimentally investigated in a systematic fashion?

72. What was the body plethysmograph and why was it invented?

73. What famous psychologist published articles in Harper's, McCall's, Liberty, Collier's, and Cosmopolitan magazines?

74. What famous psychobiologist kept a stuffed albino rabbit that had been a childhood pet?

75. When and by whom was the first experiment on conditioning published and what type of response was investigated?

76. With whom did Wundt study to receive his doctorate in physiology?

77. Who organized the founding of the American Psychological Association in 1892 ?

78. Who wrote, in his last article in 1959, "In the end, the only sure criterion is to have fun. And I have had fun"?

79. Who invented the mirrored tachistoscope?

80. What journal publication was privately owned by Warren prior to being sold to the APA in 1924?

81. What psychologist, himself deaf in one ear, made the discovery that pure tones cannot be localized in monaural hearing?

82. For what industrial company did Boring work prior to his graduate training in psychology?
83. What was John Watson's middle name?

84. Who said, "As a psychologist, I feel that the strength of the evidence must be proportional to the strangeness of the event'?

85. What learning theorist contracted typhoid fever as a young man and, as a result, became amnesic for several weeks?

86. What developmental psychologist wrote his dissertation on mollusks?

87. Where did L. L. Thurstone work before teaching engineering courses at the University of Minnesota?

88. To what university was Carl Rogers referring in the following quote? "What I did not foresee or recognize was that the department had come to place such stress on 'rigorous' examinations, of failing large proportions of students, that no one in any field could turn out a significant number of Ph.D.s. In the department as a whole-though it took me a number of years to realize thisabout one out of seven of our carefully chosen graduate students ever received the Ph.D. Some were failed, some of the most creative minds and the best clinicians left in disgust, and I was in the peculiar position of training graduate students who had only a minute chance (a chance which did not have much to do with merit) of obtaining a degree."

89. What was J. P. Guilford's first name?

90. What was the name of the Greenwich astronomer fired by Maskelyne in 1796 because of a discrepancy between his and Maskelyne's recordings of stellar transit times?

91. Who is credited with producing the first works on comparative psychology?

92. What was the name of Clever Hans' owner?

93. What French psychologist published papers on such varied topics as the psychic life of insects, chess playing, anthropometrics, perception of ink blots, and graphology?

94. Who made the following statement? "I work on the assumption that every apparently free mental choice that I or anyone else has ever made must in fact have been causally predetermined in the preceding brain states and related events. This means that any decision in which any of us has ever engaged could not possibly have had any other outcome. . . . It means that we are now and have always been imprisoned, as it were, in the inexorable onward march of causal determinism."

a. B. F. Skinner

b. Roger Sperry

c. John Watson

d. E. B. Titchener

e. W. Penfield

95. What differential psychologist dropped out of high school in 1924 , but then entered college and earned her Ph.D. at the age of 21 ?

96. Who is largely credited with the establishment of experimental psychology laboratories in Great Britain?

97. What was G. Stanley Hall's first name?

98. Independently of Mach, who discovered the function of the semicircular canals in 1875 ?

99. Name the first three presidents of the APA in order.

100. Who said, "Children under three or four, and insane persons, especially idiots, are unusually hard to hypnotize'?

a. Freud

b. Janet

c. Breuer

d. James

e. Moll

101. Name the three people who are credited with first applying signal detection theory to sensory processes.

102. In what year was Psychology Today first published?

103. From what university did Joyce Brothers receive her Ph.D.?

Questions 104-110: Identify the following effects named after their discoverers:

104. Kamin effect

105. McCollough effect 
106. Zeigarnik effect

107. von Restorff effect

108. Crespi effect

109. Coolidge effect

110. Goodrich effect

111. Define Weber's law.

112. What was the title of Edna Heidbreder's book on the history of schools of psychology?

113. From whose writing is the following quote taken? "If I attempt to analyze a man's entire mind, I find connections of varying strength between (a) situations, elements of situations, and compounds of situations and (b) responses, readiness to respond, facilitations, inhibitions, and directions of responsts. If all these could be completely inventoried . . . it seems to me that nothing would be left out ... Learning is connecting. The mind is man's connection system."

114. What person authored (or coauthored) the following two books: The Psychology of Great Calculators and Chess Players and Introduction to Experimental Psychology?

115 . Who is generally credited with the remark, "Nothing is so practical as a good theory'?

116. A description of the $t$ test was first published in 1909 under the pseudonym "student." Give the real name of its inventor.

Questions 117-119: Give the name of the person for whom the psychology building is named at the following schools:

117. University of Wisconsin

118. University of California-Berkeley

119. Brown University

120. What name did William McDougall give his theory that many behaviors are based on instincts?

\section{ANSWERS}

1. Hamilton College. 2. Franz Brentano. 3. 1879, 1885. 4. G. Stanley Hall, William James. 5. E. B. Titchener. 6. J. M. Cattell. 7. J. R. Angell. 8. John B. Watson. 9. Tenerife. 10. Tolman. 11. Wisconsin. 12. Johns Hopkins, John B. Watson. 13. Dollard, Doob, Miller, Mowrer, and Sears. 14. 1904. 15. 1916, John B. Watson. 16. J. M. Cattell and J. M. Baldwin. 17. Journal of Animal Behavior (until it merged with Psychobiology in 1911). 18. (c) William James. 19. Mary W. Calkins, 1905. 20. (e) Samuel W. Fernberger. 21. Gall and/or Spurzheim. 22. Ebbinghaus. 23. Albee, Clark, Anastasi, Tyler, Bandura, Campbell. 24. Helmholtz. 25. Carl Jung. 26. (a) Hull. 27. Merkel, 1885. 28. Cambridge. 29. Robert Leeper. 30. Wolfgang Köhler, Carl Rogers, and Kenneth Spence. 31. Sessions. 32. Fechner. 33. Titchener. 34. Galton. 35. James and Eleanor Gibson (1961, 1968). 36. G. Stanley Hall, 1887. 37. Petrovich. 38. (b) William James. 39. Cattell. 40. 1948. 41. Richard Walters. 42. John Watson. 43. Michael Posner. 44. Leibnitz. 45. 1912. 46. Broadbent (1957). 47. Tolman (1932). 48. Kohler, 1917 in German; 1925 in English. 49. Lorenz (1966). 50. Skinner (1937). 51. Hull (1953). 52. Dollard
\& Miller (1950). 53. Guthrie and Horton (1946). 54. Lewin (1935). 55. Gordon and Floyd Allport $(1964,1965)$, John and Richard Atkinson $(1977,1979)$, Donald and Angus Campbell $(1970,1974)$, and Neal and George Miller $(1959,1963)$. 56. Bolton. 57. Jaensch (1920). 58. Sir Ronald Fisher. 59. Thomasius (17th century). 60. "In no case may we interpret an action as the outcome of the exercise of a higher psychical faculty if it can be interpreted as the outcome of the exercise of one which stands lower in the psychological scale." 61. Galton. 62. Physiology of the eye. 63. John Watson's research assistant and second wife. 64. (c) S. Freud. 65. Kent and Rosanoff, 1910. 66. Exner (1873). 67. Writer. 68. Bechterev. 69. Wheatstone. 70. In the basement of William James' home at Harvard. 71. Jenkins and Dallenbach, 1924. 72. It was a device designed to measure oxygen consumption and was used to study bodily changes as a result of emotion. 73. John Watson. 74. Yerkes. 75. Twitmeyer (1902); knee jerk reflex. 76. Muller. 77. G. Stanley Hall. 78. Tolman. 79. Dodge. 80. Psychological Review. 81. Frank Angell. 82. Bethlehem Steel. 83. Broadus. 84. Carl Seashore. 85. Clark Hull. 86. Jean Piaget. 87. Thomas Edison's laboratory. 88. Wisconsin. 89. Joy. 90. Kinnebrook. 91. G. J. Romanes. 92. Mr. von Osten. 93. Binet. 94. (b) Roger Sperry. 95. Anne Anastasi. 96. James Ward. 97. Granville. 98. Joseph Breuer. 99. Hall, Ladd, James. 100. (d) James. 101. Swets, Birdsall, and Tanner. 102. 1967. 103. Columbia. 104. Retention of an avoidance response is best at intermediate intervals after conditioning. 105. Color afterimages from grated visual stimuli depend on direction of gaze. 106. Memory for tasks that a subject is unable to complete during study is better than memory for completed tasks. 107. If one item in a list is very different from other list items, it will be recalled better than the remaining items. 108. Successive contrast produced by changing reward magnitudes-relative to a control group receiving a constant number of pellets, rats shifted from a small to a large number run faster, and those shifted from a large to a small number run slower. 109. The stimulating effect of a new partner after sexual intercourse with another. 110. Animals trained on a partial schedule run faster in the early sections of a runway, but animals on a continuous schedule run faster on the final section of the runway. 111. The ratio of the change in stimulus intensity to intensity of a standard stimulus necessary to produce a just noticeable difference is a constant. 112. Seven Psychologies. 113. E. L. Thorndike. 114. Alfred Binet. 115. Kurt Lewin. 116. William Sealy Gosset. 117. W. J. Brogden. 118. E. C. Tolman. 119. W. S. Hunter. 120. Hormic psychology.

\section{NOTE}

1. This test was first unveiled at the meetings of GUV (Gesellschaft für Unendliche Versuchen) in December, 1984, although not exactly in this form. James $H$. Neely helped prepare the form of the test used on that occasion, although he enthusiastically declined the opportunity to be coauthor of this paper.

(Manuscript received for publication February 26, 1985.) 